\title{
Correction to: Tribological investigation of sunflower and soybean oil with metal oxide nanoadditives
}

\author{
Rupesh Kumar $^{1}$ 'R. K. Gautam ${ }^{1}$
}

(c) The Author(s), under exclusive licence to Springer-Verlag GmbH Germany, part of Springer Nature 2022

\section{Correction to: Biomass Conversion and Biorefinery} https://doi.org/10.1007/s13399-022-02411-6

During the production process, an incorrect value has been written in section 3.6, paragraph 3 .

The original article has been corrected.

Publisher's Note Springer Nature remains neutral with regard to jurisdictional claims in published maps and institutional affiliations.

The original article can be found online at https://doi.org/10.1007/ s13399-022-02411-6.

\footnotetext{
R. K. Gautam

rkg.mec@itbhu.ac.in

1 Department of Mechanical Engineering, Indian

Institute of Technology (Banaras Hindu University),

Varanasi 221005, India
} 